\title{
Penentuan Patahan dan Saluran Fluida Panas Bumi Rajabasa Bagian Selatan dengan Kombinasi Metode Second Horizontal Derivatif (SHD) dan Audio Magnetotelluric (AMT)
}

\author{
Nandi Haerudin ${ }^{1}$, Dikpride Despa ${ }^{2}$ dan Suharno ${ }^{3}$ \\ ${ }^{1)}$ Program Profesi Insinyur, Universitas Lampung \\ ${ }^{2)}$ Teknik Elektro, Fakultas Teknik, Universitas Lampung \\ ${ }^{3)}$ Teknik Geofisika, Fakultas Teknik, Universitas Lampung \\ Jl. Prof. Sumantri Brojonegoro No.1 Bandar Lampung 35145
}

Corresponding author: nandi.haerudineeng.unila.ac.id

Intisari - Patahan merupakan media yang menjadi saluran fluida panas bumi dari reservoir berpindah ke permukaan. Penentuan patahan dan pola aliran menjadi sangat penting dalam eksploasi panas bumi untuk mengetahui lokasi reservoir secara tepat. Hal inilah yang menjadi tujuan dari penelitian ini. Metode yang dipakai adalah Second Horizontal Derivatif (SHD) dari data gravitasi dan metode Audio Magnetotelluric (AMT). Hasil yang didapatkan menujukkan, patahan yang terbentuk berupa patahan turun ke arah barat laut menuju arah tengah Gunung dan pusat saluran fluida berada di area antara kunjir dan Cugung.

Kata kunci - Patahan, saluran fluida, reservoir, Rajabasa bagian Selatan

Abstract - Fracture/Fault is a medium that is a channel of geothermal fluids from the reservoir to the surface. Determination of faults and flow patterns becomes very important in geothermal exploitation to find out the exact location of the reservoir. This is the aim of this research. The method used is the Second Horizontal Derivative (SHD) of gravity data and the Audio Magnetotelluric (AMT) method. The results obtained show that the fracture formed in the form of a fault descends northwest toward the middle of the mountain and the center of the fluid channel is in the area between Kunjir and Cugung.

Keywords - Fault, fluid channel, reservoir, southern Rajabasa

\section{PENDAHULUAN}

Sebuah manifestasi yang muncul di permukaan menunjukkan adanya sumber panas bumi di kedalaman yang dikenal dengan reservoir. Fluida panas bumi tidak mungkin sampai ke permukaan tanpa adanya media yang menjadi salurannya. Dalam kasus fluida panas bumi, mereka mengalir melalui patahan atau rekahan yang terbentuk oleh proses geologi. Kadang kemunculan manifestasi tidak persis di atas reservoir. Hal itu tergantung arah saluran yang membawanya.

Untuk mendapatkan letak reservoir yang tepat, maka jenis patahan dan arah saluran fluida menjadi penting untuk diketahui dengan tepat. Ada patahan yang dapat menyalurkan (leaking) dan ada yang tidak (sealing). Hanya patahan leaking yang bisa menjadi saluran fluida panas bumi.

Tujuan dari penelitian ini adalah menentukan jenis patahan dan saluran fluida panas bumi dengan menggunakan perpaduan metode Second Horizontal Derivatif (SHD) dari data gravitasi dipadukan dengan metode Audio Magnetotellurik/ magnetotelluric (AMT)

\section{DASAR TEORI}

\section{Gradien horizontal data gravitasi $1 D$}

Gradien horisontal adalah sebuah metode filter yang bertujuan mengetahui perubahan mencolok dan tiba-tiba kearah lateral. Metode gradien horizontal dapat digunakan untuk menentukan lokasi batas kontak kontras densitas horizontal dari data gravitasi 
[1]. Teknik ini sering digunakan pada metode gravitasi untuk mengetahui perubahan densitas pada batas kontak antara dua medium. Perubahan paling curam akan terlokalisasi di atas tepi/bidang batas medium.

Pada Gambar 1 diperlihatkan bagaimana profil respon dari anomali gravitasi dan gradien horizontal yang disebabkan oleh sumber tubuh tabular. Puncak anomali gravitasi berada pada bagian tengah tubuh, sedangkan puncak respon gradien horizontal berada pada tepiannya. Jika tepian itu adalah batas kontak antara dua medium batuan, maka analisis ini dapat digunakan untuk menentukan jenis struktur geologi bawah permukaan seperti patahan naik atau turun, intrusi atau cekungan [2].

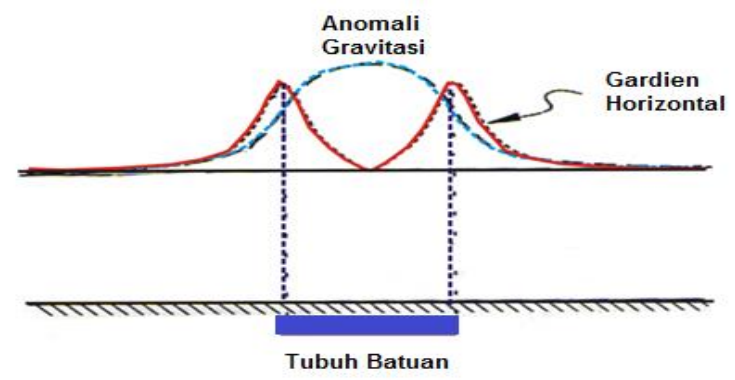

Gambar 1 Anomali gravitasi dan gradien horizontal pada model tabular (Blakely, 1996)

Pengertian gradien horizontal $(\mathrm{GH})$ adalah turunan pertama pertama pada arah horizontal atau First Horizontal Derivative (FHD). Gradien horizontal pada data anomali gravitasi adalah perubahan nilai anomali gravitasi dari satu titik ke titik lainnya dengan jarak tertentu. Setelah diturunkan satu kali lagi, akan didapatkan gradien horizontal kedua atau Second Horizontal Derivative (SHD).

Kelebihan dari metode gradien horizontal adalah metode ini tidak rentan terhadap noise karena hanya memerlukan perhitungan turunan horizontal pertama yang dikuadratkan dari data. Metode ini dapat digunakan untuk menggambarkan struktur geologi bawah permukaan yang dangkal maupun dalam. Amplitudo dari gradien horizontal ditunjukkan sebagai berikut:

$$
F H D=\sqrt{\left(\frac{\partial g}{\partial x}\right)^{2}+\left(\frac{\partial g}{\partial y}\right)^{2}}
$$

dengan ( $\frac{\partial g}{\partial x}$ dan $\left.\frac{\partial g}{\partial y}\right)$ adalah turunan horizontal gravitasi pada arah $x$ dan $y$. Satuan dari FHD pada data gravitasi adalah $\mathrm{mGal} / \mathrm{m}$. Analisis ini sesuai dengan persamaan Laplace untuk anomali gravitasi di permukaan yang diberikan sebagai berikut:

$$
\begin{gathered}
\nabla^{2} \Delta g=0 \\
\frac{\partial^{2} \Delta g}{\partial x^{2}}+\frac{\partial^{2} \Delta g}{\partial y^{2}}+\frac{\partial^{2} \Delta g}{\partial z^{2}}=0
\end{gathered}
$$

Sehigga bila diasumsikan turunan kedua arah $y$ mempunyai nilai konstan maka persamaannya menjadi:

$$
\frac{\partial^{2} \Delta g}{\partial z^{2}}=-\frac{\partial^{2} \Delta g}{\partial x^{2}}
$$

Second Horizontal Derivative dari suatu anomali gravitasi permukaan adalah sama dengan negatif dari derivatif orde dua vertikalnya. Nilai $g_{l}$ hingga $g_{n}$ merupakan nilai anomali Bouguer untuk setiap stasiun pengukuran yang memiliki jarak tertentu $\left(x_{1^{-}}\right.$ $\left.x_{n}\right)$ dengan spasi pengukuran $(\Delta x)$ tertentu pula. Maka Second Horizontal Derivativenya dapat dituliskan sebagai berikut:

$$
\begin{gathered}
\frac{\partial^{2} \Delta g}{\partial x}=\frac{g_{i+1}-g_{i}}{\Delta x} \\
\frac{\partial^{2} \Delta g}{\partial x^{2}}=\frac{\frac{g_{i+1}-g_{i}}{\Delta x}-\left(\frac{g_{i}-g_{i-1}}{\Delta x}\right)}{\Delta x} \\
\frac{\partial^{2} \Delta g}{\partial x^{2}}=\frac{g_{i+1}+g_{i-1}-2 g_{i}}{\Delta x^{2}}
\end{gathered}
$$

Dari analisa Second Horizontal Derivative (SHD) didapat kriteria untuk patahan naik dan turun yaitu:

1. Untuk patahan turun

$$
\left(\frac{\partial^{2} \Delta g}{\partial x^{2}}\right)_{m a k s}<\left|\left(\frac{\partial^{2} \Delta g}{\partial x^{2}}\right)_{\text {min }}\right|
$$

2. Untuk patahan naik

$$
\left.\left(\frac{\partial^{2} \Delta g}{\partial x^{2}}\right)_{m a k s}\right\rangle\left|\left(\frac{\partial^{2} \Delta g}{\partial x^{2}}\right)_{\min }\right|
$$

Kriteria di atas dapat dibuktikan dengan membuat model sintetis lalu dilakukan analisa SHD pada model itu [3]. 
Konsep Dasar Metode Magnetotelluric (MT) dan Audio Magnetotelluric (AMT)

Metode magnetotelurik atau magnetotelluric (MT) adalah metode geofisika yang memanfaatkan medan elekto magnetik (EM) alami sebagai sumber gelombang atau sumber energi untuk mengetahui struktur tahanan jenis bawah permukaan. Magnetotellurik merupakan metode sounding yang mengukur secara pasif medan elektromagnetik alam yang dipancarkan oleh bumi. Medan EM yang digunakan mempunyai rentang frekuensi yang panjang sehingga mampu menyelidiki bawah permukaan dari kedalaman puluhan hingga ribuan meter.

Sumber medan elektromagnetik pada frekuensi rendah (kurang dari $1 \mathrm{~Hz}$ ) berasal dari interaksi antara partikel yang dikeluarkan oleh matahari yang menyebabkan resonansi lapisan ionosfer bumi, sedangkan frekuensi tinggi (lebih dari $1 \mathrm{~Hz}$ ) berasal dari aktivitas kilat.

Medan listrik dan medan magnet berhubungan dengan arus telurik yang mengalir di bumi sebagai akibat dari variasi medan elektromagnetik alami bumi yang bergantung pada sifat kelistrikan terutama konduktivitas medium [4]. Gelombang elektromagnetik yang sampai di permukaan tanah, akan menginduksi arus pada lapisanlapisan di bawah permukaan bumi yang dianggap konduktor. Arus hasil induksi ini disebut arus telluric atau arus eddy.

Arus telluric pada lapisan-lapisan bumi menyebabkan timbulnya medan elektromagnetik sekunder yang kemudian akan dipancarkan kembali ke seluruh arah sampai di permukaan bumi. Medan elektromagnetik inilah yang akan dicatat oleh penerima untuk memperoleh informasi tentang pengukuran lapisan di bawah permukaan bumi. Informasi yang diperoleh adalah fluktuasi medan listrik dan fluktuasi medan magnet yang dihasilkan rapat arus telluric pada masing-masing lapisan.

Metode ini memanfaatkan medan elektromagnetik alam dengan frekuensi antara $10^{-4} \mathrm{~Hz}$ hingga $10^{4} \mathrm{~Hz}$. Semakin kecil frekuensi yang digunakan, maka informasi kedalaman yang diperoleh semakin dalam sehingga metode ini dapat digunakan untuk kepentingan investigasi di bawah permukaan dengan kedalaman hingga ribuan meter [5].

Dengan mengggunakan hasil pengukuran impedansi dari berbagai frekuensi yang berurutan dapat diperoleh informasi resistivitas medium sebagai fungsi kedalaman di bawah titik pengamatan tersebut dan menggambarkan struktur geologi bawah permukaannya.

Target kedalaman tergantung pada frekuensi gelombang yang digunakan. Gelombang elektromagnetik dengan frekuensi yang tinggi dapat memberikan informasi mengenai resistivitas medium dibagian yang dangkal sedangkan gelombang elektromagnetik dengan frekuensi yang rendah dapat memberikan informasi mengenai resistivitas medium dibagian yang dalam.

Metode tahan jenis (geolectrical, MT, AMT/CSAMT dan TEM) adalah metode geofisika yang paling penting dalam eksplorasi panas bumi. Alasannya adalah bahwa resistivitasnya sangat sensitif terhadap proses perubahan suhu dan panas bumi dan secara langsung terkait dengan parameter yang mengkarakterisasi Reservoir [6].

Metode MT dan AMT secara umum sama, hanya saja keduanya berbeda pada frekuensi yang digunakan. Metode AMT menggunakan frekuensi dari rentang $0,1 \mathrm{~Hz}$ hingga $10 \mathrm{kHz}$. Dengan rentang frekuensi ini, cocok untuk digunakan dalam menentukan struktur geologi di daerah panas bumi. Baik MT dan AMT/CSAMT diakui sebagai metode geofisika yang handal dalam eksplorasi panas bumi karena keduanya menghasilkan struktur resistivitas yang kurang lebih terkait dengan rezim suhu bawah permukaan. Namun, dari sudut pandang empiris terkadang CSAMT memberikan hasil yang lebih baik daripada metode lainnya misalnya MT di eksplorasi panas bumi [7].

Salah satu keberhasilan metode ini adalah mampu memetakan zona resistivity untuk memahami reservoir, jalur fluida termal, dan sumber panas di lapangan panas bumi Mapamyum (QP) di barat daya Tibet [8]. Selain untuk eksplorasi panasbumi, metode AMT berhasil digunakan untuk mengevaluasi mineralisasi timah-seng tersembunyi di bidang bijih timah-seng 
Yuele, Daguancounty, NE provinsi Yunnan, Cina [9] dan memodelkan zona sesar Cimandiri Cianjur [10].

\section{METODE PENELITIAN}

Penelitian ini dilakukan berdasarkan sistematika yang sesuai dengan kaidah metode ilmiah yang meliputi: pengambilan data, pengolahan data, pemodelan dan interpretasi, analisis dan kesimpulan. Pada penelitian ini, digunakan data primer yang diambil di lapangan dan data sekunder dari Badan Geologi. Data gravitasi dari Badan Geologi berupa data anomali Bouguer lengkap yang diambil dalam kegiatan survei pendahuluan lanjutan. Data anomali Bouguer ini ditampilkan dalam bentuk peta kontur, kemudian dibuat irisan penampang lintang pada daerah anomali gravitasi rendah atau kontur yang berubah secara drastis. data irisan penampang lintang diolah dengan metode Second Horizontal Derivative (SHD) untuk mendapatkan posisi patahan dan arah kemiringannya.

Pengukuran data penelitian dilakukan di gunung api Rajabasa bagian selatan diantara fumarol Kunjir dan fumarol Cugung. Data yang didapatkan dari perekaman alat berupa data frekuensi, koherensi, apparent resistivity dan fase. Frekuensi yang digunakan yaitu frekuensi audio (audio frequency band) dari rentang $0,1 \mathrm{~Hz}$ hingga $10 \mathrm{kHz}$. Data diolah menggunakan perangkat lunak Microsoft Excel, Notepad, IPI2Win(MT) dan Surfer. Hasil pengolahan data berupa kontur tahanan jenis berdasarkan kedalaman yang sama dan kontur kedalaman pada tahanan jenis yang sama, kemudian diinterpretasikan secara kuantitatif dan kualitatif.

Peralatan yang digunakan dalam penelitian dengan menggunakan metode AMT adalah satu set Stratagem versi 2671601 Rev.D yang berupa komponen penerima (receiver) standar dan beberapa perangkat tambahan lainnya sebagai pendukung pelaksanaan penelitian.

Setelah data pengukuran diperoleh, dilakukan pemilihan data berdasarkan pada nilai koherensinya. Data yang dianggap baik dan dipilih untuk diolah adalah data yang mempunyai nilai koherensi besar. Nilai koherensi menunjukkan perbandingan antara medan E prediksi dan medan E observed (data lapangan). Data lapangan yang berupa fungsi frekuensi diubah dalam bentuk akar period, yang selanjutnya dibuat grafik. Dilakukan smoothing (penghalusan data) dengan cara rata-rata bergerak (moving average). Data hasil smoothing merupakan data masukan (input) untuk interpretasi 1D menggunakan perangkat lunak IPI2Win(MT). Hasil yang diperoleh berupa tahanan jenis pada lapisan batuan dengan ketebalan dan kedalaman tertentu untuk setiap pengukuran. Dari hasil yang diperoleh dibuat kontur tahanan jenis berdasarkan kedalaman yang sama dan kontur kedalaman pada tahanan jenis yang sama. Interpretasi kuantitatif dilakukan dengan menginterpretasikan hasil pemodelan 1D yang berupa urutan nilai tahanan jenis pada ketebalan dan kedalaman tertentu. Interpretasi kualitatif dilakukan dengan menginterpretasikan kontur tahanan jenis berdasarkan kedalaman yang sama dan kontur kedalaman pada tahanan jenis yang sama dengan menggunakan perangkat lunak Surfer 11. Rangkain alur penelitian ditampilkan pada Gambar 2

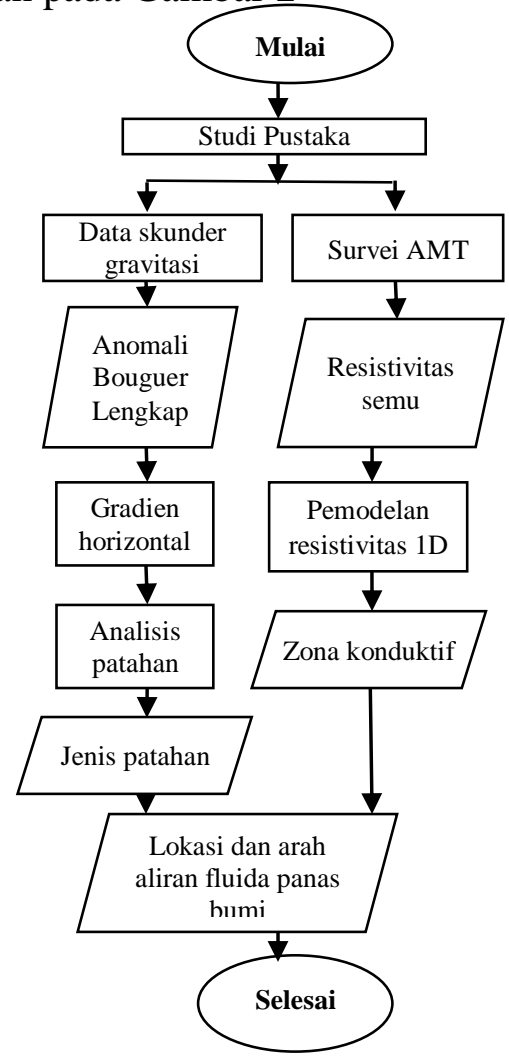

Gambar 2 Diagram alir penelitian 


\section{HASIL DAN PEMBAHASAN}

Analisis second horizontal derivative (SHD) data gravitasi

Analisa Second Horizontal Derivative (SHD) dapat menggambarkan sumbersumber anomali dan digunakan untuk menentukan jenis struktur geologi bawah permukaan seperti patahan naik atau turun, intrusi atau cekungan. Metode gradien horizontal digunakan untuk menentukan lokasi batas kontak kontras densitas horizontal dari data gravitasi. Pada data gravitasi G. Rajabasa bagian selatan dibuat beberapa irisan seperti pada Gambar 3 .

Hasil FHD dan SHD untuk irisan aa' ditampilkan pada Gambar 4. Terlihat adanya profil kurva gradien yang bernilai tinggi atau curam pada Kurva FHD yang mengindikasikan adanya struktur patahan di lokasi itu. Posisinya pada 568700 - 571200 $\mathrm{mE}$. Prosisi ini hampir sama dengan posisi manifestasi Kunjir. Setelah diturunkan sekali lagi, terlihat pasangan nilai posistif dan negatif. Nilai puncak positif (maksimum) lebih kecil dari nilai puncak negatif (minimum) dan berada di sebelah kiri.

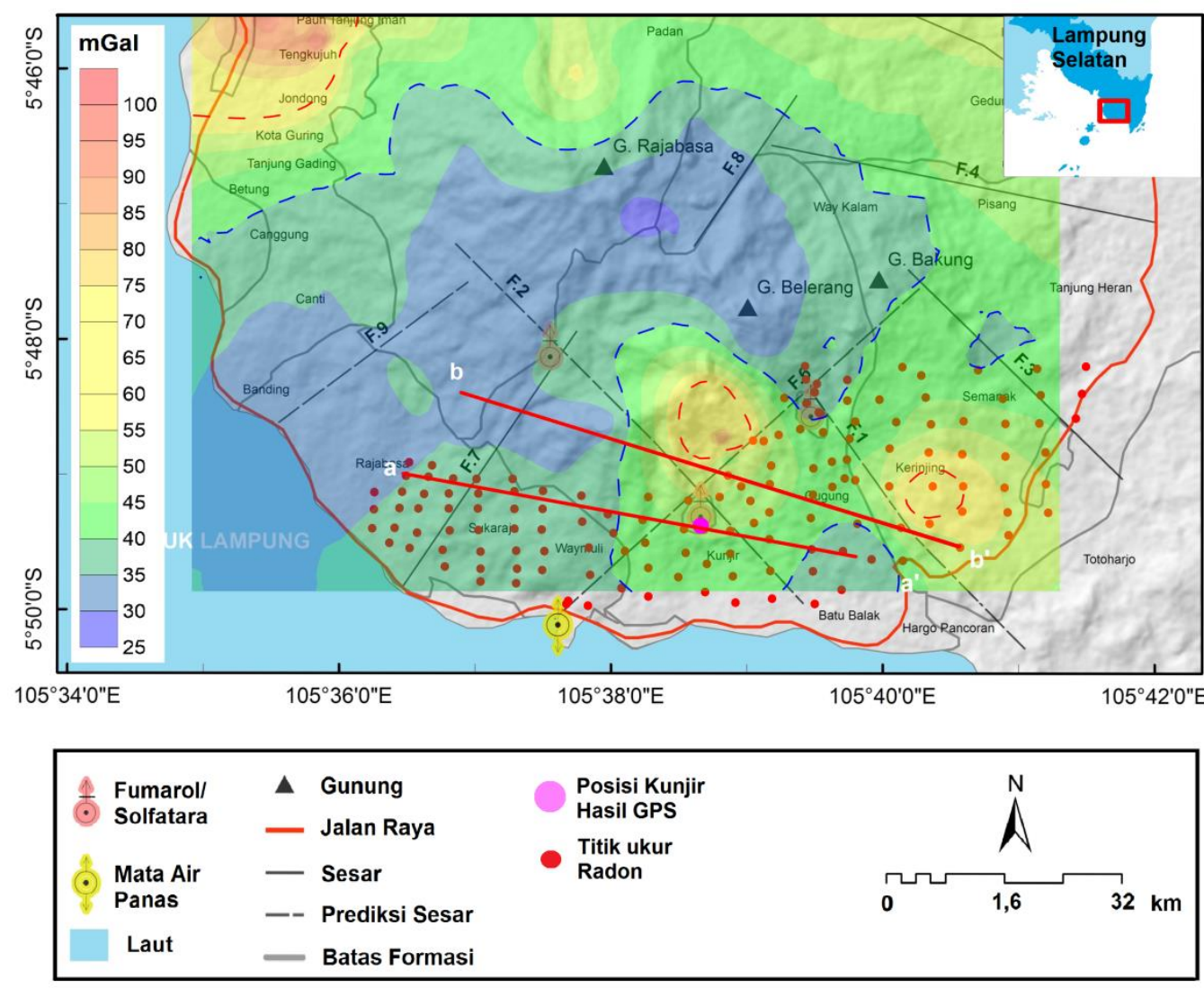

Gambar 3 Irisan-irisan untuk second horizontal derivative (SHD)

Untuk penentuan jenis struktur geologi dan arah kemiringannya digunakan tabel analisis dari Cordell seperti yang tertuang dalam Tabel 5.1. Patahan turun ditentukan dengan nilai maksimum (puncak positif) yang lebih kecil dibandingkan dengan nilai minimum (puncak negatif). Ketika nilai minimum yang lebih besar tadi berada disebelah kiri, maka hal itu menunjukkan bahwa arah bidang patahan adalah turun ke kanan. Untuk patahan naik, berlaku aturan sebaliknya. Mengacu pada Tabel 5.1, struktur geologi yang yang ditemukan pada irisan $\mathrm{A}$ adalah patahan turun/patahan normal kearah kiri atau barat laut.

Untuk menentukan struktur geologi yang ada pada irisan bb', dicari dengan cara yang sama pada irisan aa'. Hasilnya ditampilkan pada Gambar 5. Terlihat ada kurva gradien yang yang bernilai tinggi/curam pada posisi 568500 - 571500. Setelah diturunkan sekali lagi, terlihat nilai maksimum (positif) lebih 
kecil daripada negatif dan nilai positif berada disebelah kiri. Hal ini menunjukkan jenis struktur yang ditemukan dengan metode SHD gravitasi pada irisan bb' berupa patahan turun ke arah kiri atau arah barat laut atau sama dengan patahan pada irisan aa'.

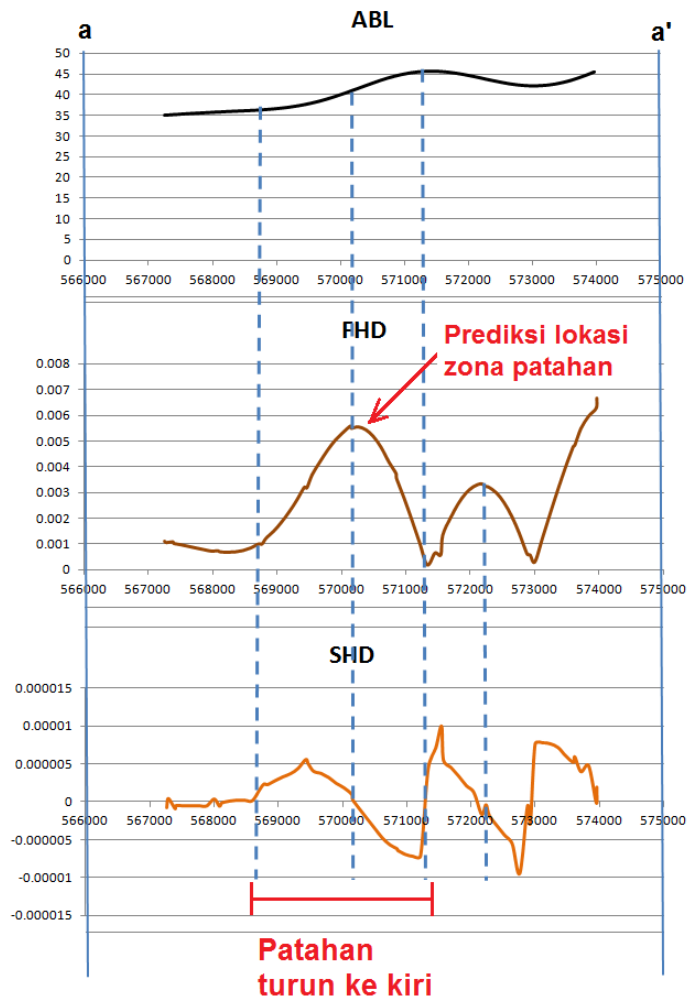

Gambar 4 Hasil first horizontal derivative/FHD

(a) dan second horizontal derivative/SHD (b) pada irisan aa'

Tabel 5.1 Penentuan sesar dan arah kemiringan berdasarkan second horizontal derivative (SHD) pada data gravitasi [1]

\begin{tabular}{|c|c|c|c|}
\hline SHD & Tipe & \multicolumn{2}{|c|}{ Arah Kemiringan } \\
\cline { 3 - 4 } & Sesar & Ke kanan & Ke kiri \\
\hline $\mathrm{SHD}_{\max }>\mid \mathrm{SHD}_{\min }$ & Naik & & \\
\hline $\mathrm{SHD}_{\max }<\mid \mathrm{SHD}_{\min }$ & & Turun & \\
& & $\checkmark$ & \\
& & & \\
& & & \\
\hline
\end{tabular}

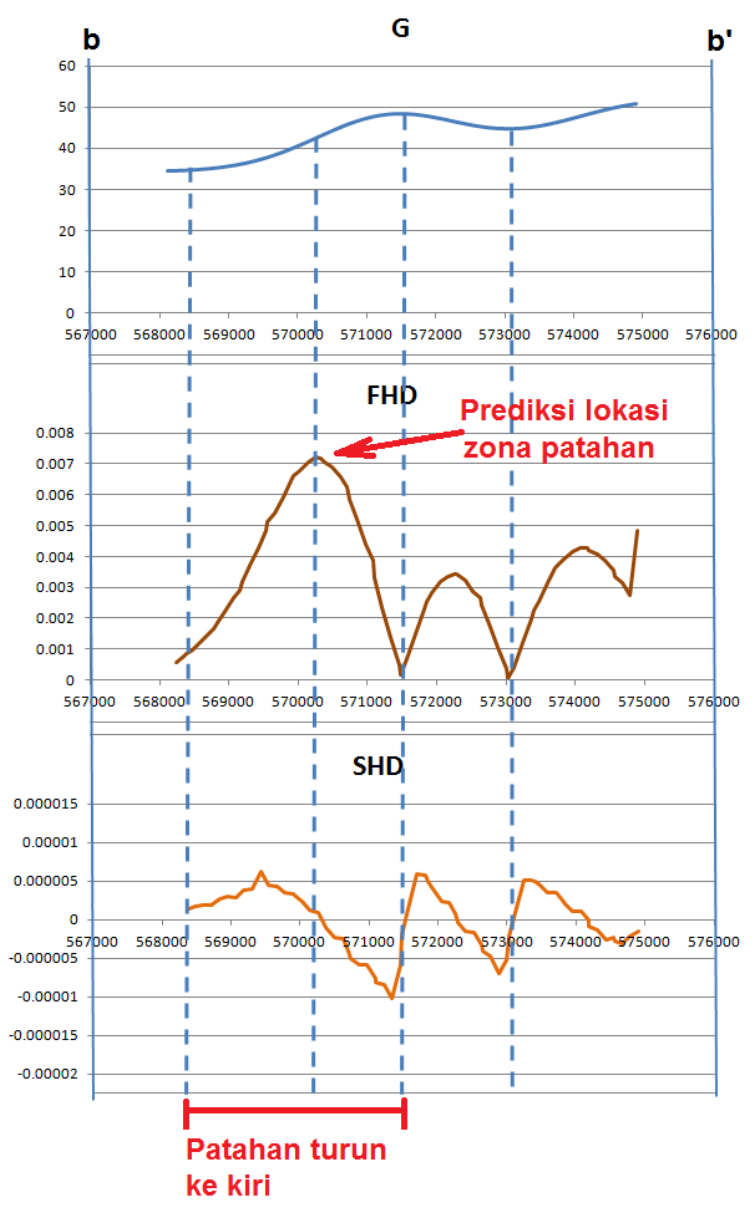

Gambar 5 Hasil first horizontal derivative/FHD (a) dan second horizontal derivative/SHD (b) pada irisan bb'

Pada Gambar 6 ditunjukkan posisi patahan hasil FHD dan SHD untuk irisan aa" dan bb' pada peta dasar. Patahan utama irisan aa' terletak berhimpit dengan lokasi manifestasi Kunjir hasil pengukuran lapangan dengan GPS, sedangkan patahan utama irisan bb' berhimpit dengan patahan F.6. Patahn F.6 diprediksi sebagai patahan turun dengan bidang turun ke arah barat laut. Dengan begitu, hal ini menjadi verifikasi bahwa metode FHD dan SHD dapat digunakan untuk menentukan lokasi dan jenis patahan. 


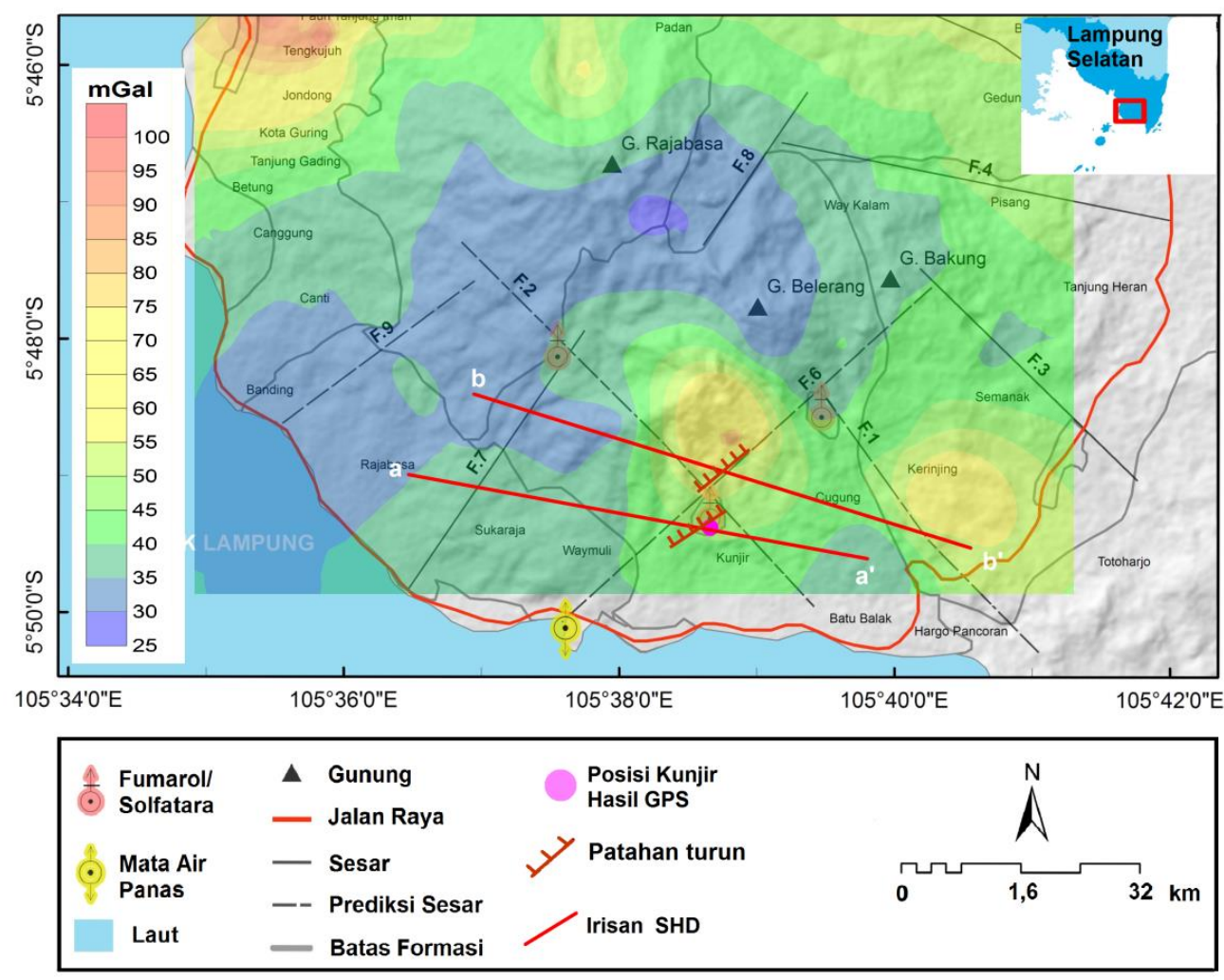

Gambar 6 Posisi patahan hasil second horizontal derivative (SHD) pada peta dasar

\section{Pengolahan Data dan Interpretasi Metode AMT}

Data awal yang diperoleh dari hasil pengolahan stratagem versi 2671-01 REV.D berupa komponen frekuensi, koherensi, apparent resitivity dan fase. Data tersebut dikoreksi berdasarkan nilai koherensinya. Data yang memiliki nilai koherensi besar (mendekati nilai 1) merupakan data yang bagus. Untuk meningkatkan kualitas data, dilakukan smoothing (penghalusan data) menggunakan cara moving average. Hasilnya merupakan input (masukan) untuk pemodelan 1D menggunakan program IPI2Win(MT).

Hasil dari pengolahan dengan menggunakan program IPI2Win(MT) berupa resitivitas lapisan batuan dengan ketebalan dan kedalaman tertentu untuk setiap titik pengukuran. Titik pengukuran diberi label berdasarkan nomor 1 - 29. Gambar 7 menunjukkan hasil pengolahan pada salah satu titik yaitu titik pengukuran 16 .

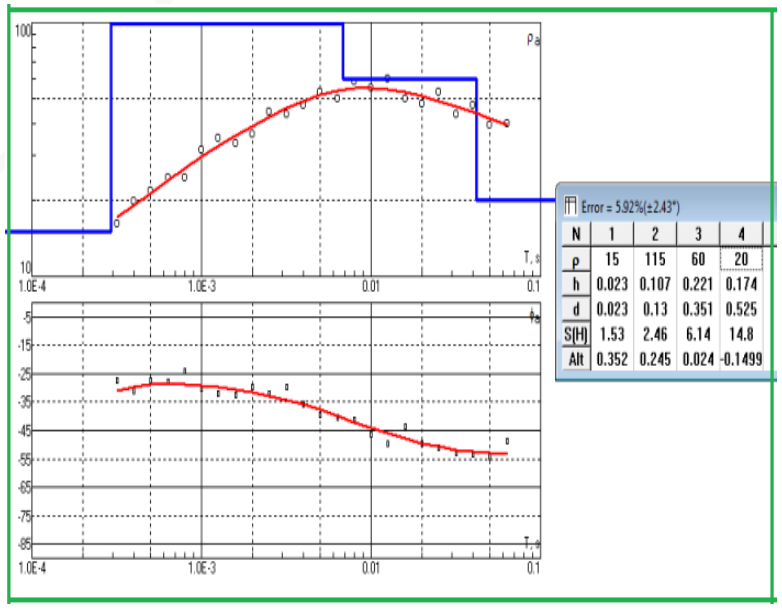

Gambar 7 Hasil pengolahan IPI2Win(MT) pada titik ukur 16

Data tahanan jenis sounding dari setiap titik pengukuran dikorelasikan berdasarkan berdasarkan kedalaman yang sama. Kedalaman yang masih bisa dideteksi mencapai $580 \mathrm{~m}$ dari MSL. Gambar 8 menunjukkan kontur tahanan jenis pada kedalman $580 \mathrm{~m}$. Nilai tahanan jenis yang terukur berkisar $20 \Omega \mathrm{m}-290 \Omega \mathrm{m}$. Terlihat adanya tahanan jenis rendah dengan nilai 20 $\Omega \mathrm{m}-100 \Omega \mathrm{m}$ di daerah antara fumarol Kunjir dan fumarol Cugung pada titik ukur 
15, 16, 20, dan 21. Daerah dengan warna merah mendominasi bagian tengara, sedangkan dearah dengan warna kuning mendominasi bagian barat laut. Kedua warna tersebut memperlihatkan adanya batas kontras yang adanya zona tahanan jenis tinggi yang melingkupi zona tahanan jenis yang lebih rendah.

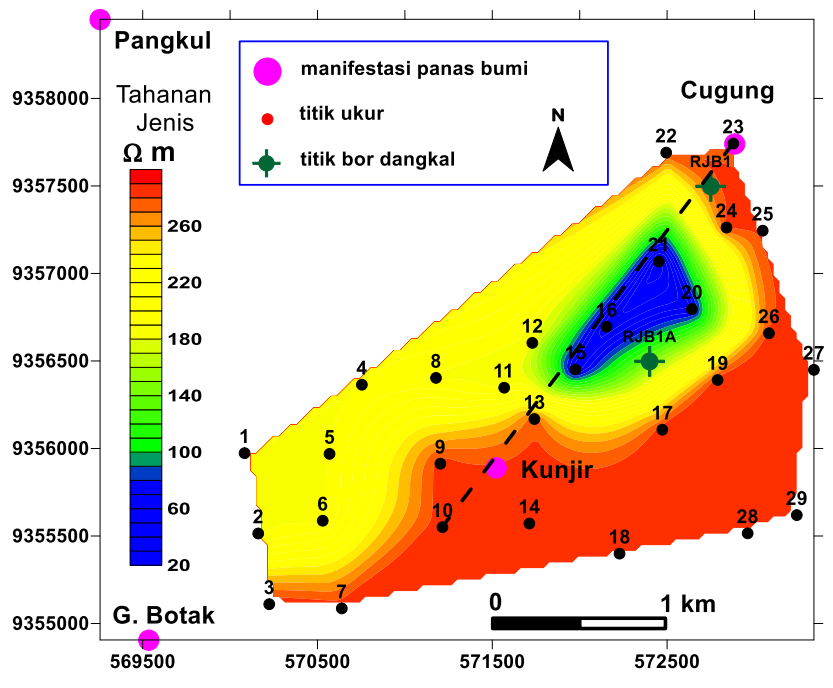

Gambar 8 Kontur tahanan jenis metode AMT pada kedalaman $580 \mathrm{~m}$

Untuk melihat penampang lintang arah vertikal, dipilih titik 10, 13, 15, 16, 21 dan 23 yang hampir membetuk satu garis lurus. Hasil rekontruksinya ditampilkan pada
Gambar 9. Terlihat ada daerah tahanan jenis tinggi (warna merah, kuning dan hijau) yang dipisahkan oleh daerah tahanan jenis rendah (warna ungu dan biru). Hal ini mengindikasikan adanya daerah yang terpatahkan dilokasi itu.

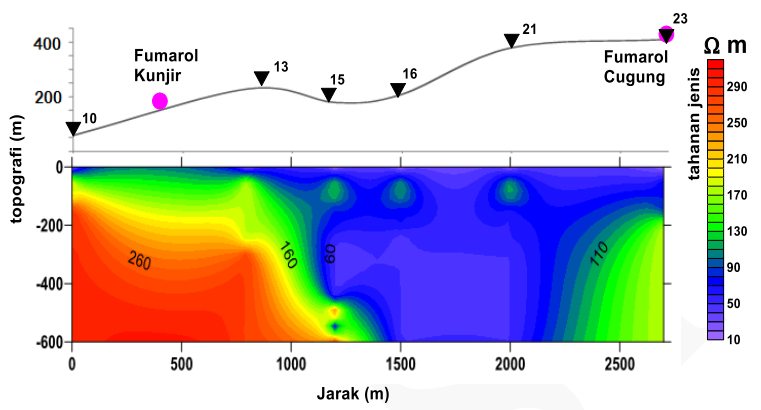

Gambar 9 Penampang lintang vertikal tahanan jenis dari metode AMT

Setelah dilakukan analisis kualitatif dan analisis kuantitatif, peta kontur tahanan jenis dari metode AMT di-overlay (dibaringkan) pada peta dasar untuk melihat posisinya di permukaan seperti yang ditunjukkan Gambar 10. Zona konduktif (tahanan jenis rendah) berada diantara patahan-patahan yang berarah barat laut - tenggara dan diantara fumarol Kunjir dan fumarol Cugung.

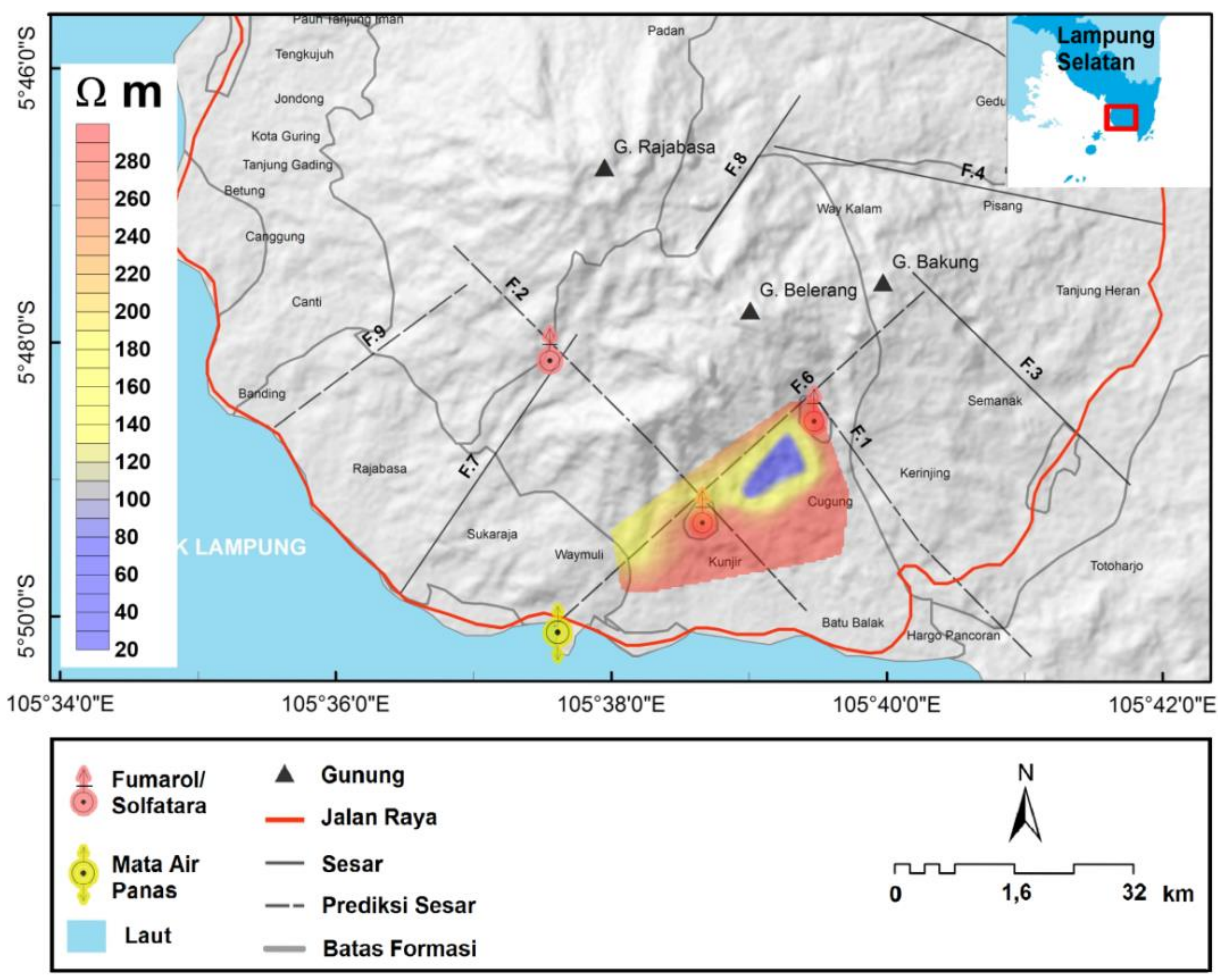


Gambar 10 Kontur tahanan jenis dari AMT pada kedalaman 580 m

Indonesian Geothermal Association Meeting \& Conference, Bandung 6-8 November, 2012.

\section{KESIMPULAN}

Metode FHD dan SHD dapat digunakan untuk menentukan lokasi dan jenis patahan. Hasil yang didapatkan menujukkan, patahan yang terbentuk berupa patahan turun ke arah barat laut menuju arah tengah Gunung dan berdasarakan analisis metode AMT didapatkan zona saluran fluida berada di area antara kunjir dan Cugung.

\section{UCAPAN TERIMA KASIH}

Kami ucapkan terima kasih kepada Badan Geolgi yang telah mengijinkan penggunaan data skunder gravitasi untuk analisis SHD.

\section{REFERENSI}

[1] L. Cordell, "Gravimetric Expression of Graben Faulting in Santa Fe Country and The Espanola Basin, New Mexico" in New Mexico Geol. Soc. Guidebook, 30th Field Conference, 1979.

[2] H. Yudianto, dan A. Setyawan, "Interpretasi Struktur Bawah Permukaan Daerah Manifestasi Panasbumi Gedong Songo Gunung Ungaran Menggunakan Metode Magnetik," Youngster Physics Journal, 2(1), 39-48, 2014.

[3] J.M. Reynolds, An Introduction To Applied And Environmental Geophysics, John Willey and Sons, 1997.

[4] A. Manzella, Geophysical Methods in Geothermal Exploration. Italian National Research Council, International Institute for Geothermal Research, Pisa, 2007.

[5] Chave and Thomson, "Bounded Influence magnetotelluric Response Function Estimation," GJI Geomagnetism, Rock Magnetism and Palaeomagnetics, Vol. 157, pp. 988 - 1006, 2004.

[6] G.P. Hersir, K. Árnason, and A. Vilhjálmsson, “3D inversion of magnetotelluric (MT) resistivity data from Krýsuvík high temperature area in SW Iceland, " in Proceedings of the Thirty-Eighth Workshop on Geothermal Reservoir Engineering Stanford University, Stanford, CA, United States, $14 \mathrm{pp}, 2013$.

[7] H. Grandis, dan P. Sumintadireja, "A Brief Review For The Proper Application Of Magnetotelluric (Mt) And Controlled- ource Audio-Frequency Magnetotelluric (Csamt) In Geothermal Exploration," in Proceedings The 12th Annual
[8] L. He, L. Chen, Dorji, X. Xi, X. Zhao, R. Chen, and H. Yao, "Mapping the Geothermal System Using AMT and MT in the Mapamyum (QP) Field, Lake Manasarovar, Southwestern Tibet," Energies 2016, 9, 855; doi:10.3390/en9100855T. T. Lap, C. Xue, A. Wei1, L. Liu, W. Li1, Q. Hu, J Li, D. Luo, S. and Zhu, T. Zhang "Application of AudioMagnetotelluric Method for Exploration the Concealed Ore-Bodies in Yuele Lead-Zinc Ore Feild, Daguan County, NE Yunnan Province, China," Journal of Geoscience and Environment Protection, 2, 35-45, 2014. http://dx.doi.org/10.4236/gep.2014. 23005.

[9] L. Handayani, Maryati, M. Kamtono, M. Mukti, and Y. Sudrajat, "Audio-Magnetotelluric Modeling of Cimandiri Fault Zone at Cibeber, Cianjur,' Indonesian Journal on Geoscience, Vol. 4 No. 1 April 2017: 39-47 